\title{
ANALISIS AKURASI DAN KARAKTERISTIK TERJEMAHAN AL-QUR'AN DAN TERJEMAHNYA BAHASA JAWA BANYUMASAN
}

\author{
Nurul Husna \\ PP. API Tegalrejo Magelang \\ nkhusnaalluthfi@gmail.com
}

\begin{abstract}
Al-Qur'an dan Terjemahnya Bahasa Jawa Banyumasan is a manifestation of the need for the contribution of the Quran to local communities, especially Banyumasan. This translation was compiled by a team of translators who were delegated by the Ministry of Religious Affairs of the Republic of Indonesia in 2011. The use of Banyumasan Javanese as an object language for translation is a fresh thing. This research is crucial as it is the first study of the Banyumasan translation of the Quran. This study aims to understand the methods of translation and also to look at the accuracy of the translation. This research is a library research using descriptive-analysis method. The references used in analyzing the accuracy of this translation are the Banyumasan dialect dictionary and linguists' statements obtained from the author's interviews. The results of this study indicate that this translation uses a contextual method with several improvisations to explain the meaning, loanwords from both Indonesian and Arabic, hierarchical language, affirmation of meaning, and also distortion of meaning that does not change the meaning of the verse.
\end{abstract}

Keywords: Quran Translation, Banyumasan Javanese Language, dialect, accuration

\begin{abstract}
Abstrak
Al-Qur'an dan Terjemahnya Bahasa Jawa Banyumasan merupakan suatu wujud dari adanya kebutuhan atas kontribusi al-Qur`an terhadap masyarakat daerah, khususnya Banyumasan. Terjemahan ini disusun oleh tim penerjemah yang ditugaskan oleh Kementerian Agama Republik Indonesia pada tahun 2011. Penggunaan bahasa Jawa Banyumasan sebagai bahasa sasaran terjemah merupakan satu hal yang baru. Penelitian ini penting karena merupakan kajian paling awal terhadap Terjemahan al-Qur`an Bahasa Banyumasan. Tujuannya untuk memahami metode penerjemahan dan juga untuk melihat akurasi terjemahannya. Penelitian ini bersifat kepustakaan dengan menggunakan metode deskriptif-analisis. Acuan yang digunakan dalam menganalisis akurasi terjemahan ini menggunakan kamus dialek Banyumasan dan pernyataan ahli dari hasil wawancara. Hasil penelitian ini menunjukkan bahwa terjemahan ini menggunakan metode kontekstual dengan beberapa improvisasi guna menjelaskan makna, penggunaan bahasa serapan, baik dari bahasa Indonesia maupun Arab, bahasa yang berhierarki, penegasan makna, dan juga distorsi makna dalam terjemahan yang tidak mengubah maksud ayat.
\end{abstract}

Kata kunci:Al-Qur`an terjemahan, Bahasa Jawa Banyumasan, dialek, akurasi 


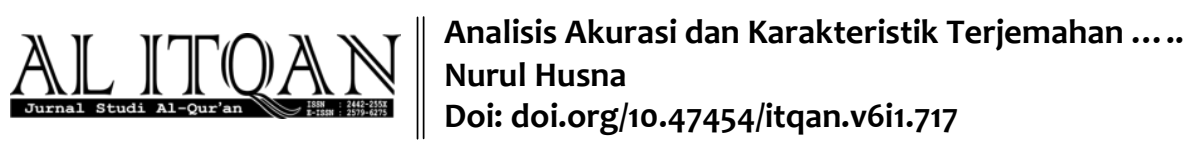

\section{A. Pendahuluan}

Terjemahan dapat digunakan sebagai alat untuk meneruskan misi-misi al-Qur`an dan keilmuan Islam kepada orang-orang non-Arab yang kurang memahami teks Arab. Dengan adanya transmisi bahasa dari bahasa al-Qur`an, yaitu bahasa Arab ke dalam bahasa lain dapat menjadikan komunikasi lebih komprehensif. Kebutuhan untuk menerjemahkan suatu teks bukanlah tanda keterbelakangan. Justru sebaliknya, tanda keterbukaan, tanda kegiatan bahwa hendak ikut serta dalam proses tukar-menukar informasi. ${ }^{1}$ Walaupun, tentu saja terjemahan bukan menjadi satu-satunya sumber rujukan dan tetap harus kembali kepada teks asli. Dengan begitu terjemah tersebut hanya sebagai upaya yang jarang sekali menemukan akurasinya seratus persen. Sebab, dialektika bahasa suatu bangsa berbeda satu sama lain. ${ }^{2}$

Penerjemahan adalah pengalihan makna dari bahasa sumber ke bahasa target, dan makna dari bahasa sumber harus dapat dipertahankan, sehingga tidak terjadi pergeseran makna pada bahasa target. Oleh karena itu, seorang penerjemah harus mengetahui kaidahkaidah bahasa sumber dan target. ${ }^{3}$ Dikatakan pula bahwa secara umum, penerjemahan memiliki dua sisi pengertian, yaitu penerjemahan dalam arti mengungkapkan atau menjelaskan dan penerjemahan dalam arti menafsirkan. ${ }^{4}$ Menjelaskan atau menafsirkan bahasa berarti mengungkap tabir ketidakjelasan dan maksud kata dalam suatu bahasa. Dengan demikian, berarti bahwa menerjemah merupakan suatu usaha untuk mengungkap pesan yang dikandung dari suatu bahasa. Tujuan pokok dari penerjemahan adalah menyampaikan pesan atau makna agar dapat dipahami. Dengan pengertian penerjemahan seperti ini, padanan gaya bahasa tidak menjadi tujuan atau sasaran utama, karena yang diperhatikan adalah penyampaian pesan yang dapat dipahami. Jika mengungkap pesan menjadi hal yang utama, maka ketepatan dalam mencari padanan makna menjadi hal wajib agar tercapainya penyampaian pesan.

Namun, bagi sebagian ahli, penitikberatan penerjemahan hanya pada padanan gagasan atau pesan seperti di atas dapat mengurangi arti dari hakikat penerjemahan itu sendiri. Karena dengan hanya melihat pada aspek padanan gagasan atau makna, dapat menimbulkan pereduksian terhadap gaya (style) bahasa sumber dan unsur-unsur lain yang terkait dengannya. Oleh karena itu, memperhatikan padanan gagasan atau makna saja tidak cukup

\footnotetext{
${ }^{1}$ A. Widyamartaya, Seni Menerjemahkan (Yogyakarta: Kanisius, 2012), hlm. 9.

${ }^{2}$ Syarif, Wujud di Balik Teks: Studi Alquran dengan Pendekatan Hikmah (Bandung: Nusa Media, 2014), hlm. 72-73.

${ }^{3}$ Risnawaty, Teori Terjemahan (Tangerang: Mahara Publishing, 2016), hlm. 1.

${ }^{4}$ M. Faisol Fatawi, Seni Menerjemah (Yogyakarta: Dialektika, 2017), hlm. 2.
} 


\section{Analisis Akurasi dan Karakteristik Terjemahan ..... Nurul Husna \\ Doi: doi.org/10.47454/itqan.v6i1.717}

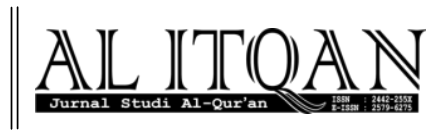

dan terlalu sempit. Penerjemahan butuh pada batasan yang lebih luas dari pada hanya sekedar mencari padanan gagasan atau makna. ${ }^{5}$

Hal-hal tersebut terjadi juga dalam kajian al-Qur`an. Ulama telah sejak lama menaruh perhatian terhadap terjemah al-Qur`an. Ulama dari periode klasik hingga kontemporer telah melakukan penerjemahan al-Qur`an dengan berbagai corak, metode, bahasa, dan pendekatan yang berbeda-beda. ${ }^{6}$ Dinamika penerjemahan al-Qur`an berkembang sesuai dengan tuntutan zaman. Seiring dengan adanya islamisasi, proses penerjemahan al-Qur`an di Indonesia terjadi secara intensif, baik secara lisan maupun tertulis. ${ }^{7}$ Penerjemahan al-Qur`an tidak hanya ke dalam bahasa Indonesia, melainkan ke dalam berbagai bahasa daerah di Indonesia. Di Jawa hingga abad ke-19, agaknya bahasa Jawa menunjukkan superioritasnya dalam hal penggunaan bahasa sasaran penerjemahan, baik al-Qur`an ataupun literatur keislaman lainnya. ${ }^{8}$

Terjemah al-Qur`an Bahasa Banyumasan merupakan produk penerjemahan al-Qur`an ke dalam bahasa Jawa dialek Banyumasan. Banyumas sendiri merupakan bagian barat daerah Jawa sepanjang aliran sungai Serayu. Aliran sungai ini berasal dari kompleks pegunungan Dieng-Sindoro-Sumbing yang mengalir ke arah barat daya sebelum akhirnya bermuara ke Samudera Hindia. Orang-orang Jawa yang tinggal di daerah ini menggunakan logat atau dialek Banyumas yang khas. ${ }^{9}$

Terjemahan ini sangat unik dan menarik dengan sejuta kearifan lokalnya. Selain dengan bahasa Jawa yang berdialek Banyumasan, terjemah ini juga ditulis oleh tim dari para ahli dibidangnya, mulai dari para $h u f a d z$, ahli bahasa dan budayawan Banyumasan, juga para cendekiawan-cendekiawan agama. ${ }^{10}$ Terjemahan ini terdiri dari satu jilid terbagi dalam 885 halaman. Ukuran terjemah ini terbilang cukup besar dan di dalamnya disusun dengan format kolom, yaitu kolom sebelah kiri adalah ayat-ayat al-Qur`an dan di sebelah kanannnya adalah terjemah ayat tersebut.

Kehadiran terjemah al-Qur`an bahasa Banyumasan ini juga menjadi sebuah jembatan masyarakat untuk berinteraksi dengan al-Qur`an. Karena, dengan membaca ayat-ayat al-

\footnotetext{
${ }^{5}$ Ibid., hlm. 3-4.

${ }^{6}$ Abdul Mustaqim, Epistimologi Tafsir Kontemporer (Yogyakarta: LKiS, 2011), hlm. 1.

${ }^{7}$ Tiwalinuddin Haris, "Al-Qur'an dan Terjemahnya Bahasa Sasak: Beberapa Catatan", Suhuf : Pengkajian AlQur`an da Buday, vol. 10, no. 1 (2017), hlm. 213. https://doi.org/10.22548/shf.v10i1.250

${ }^{8}$ Saifuddin, "Tradisi Penerjemahan Al-Qur'an ke dalam Bahasa Jawa: Suatu Pendekatan Filologis", Suhuf: Pengkajian Al-Qur`an da Budaya, vol. 6, no. 2 (2013), hlm. 233. https://doi.org/10.22548/shf.v6i2.28

${ }^{9}$ Koentjaraningrat, Kebudayaan Jawa (Jakarta: Balai Pustaka, 1994), hlm. 23.

${ }^{10}$ Tim Penerjemah, al-Qur'an dan Terjemahnya: Bahasa Jawa Banyumasan (Jakarta: Puslitbang Lektur dan Khazanah Keagamaan Badan Litbang dan Diklat Kementerian Agama Republik Indonesia, 2016), hlm. ii.
} 
Qur`an bernilai pahala, dan sekaligus memahami makna kandungannya dalam terjemahan ini. Selain untuk memperkaya khazanah penerjemahan ke dalam bahasa daerah, terjemah alQur`an bahasa Banyumasan juga digunakan untuk memperluas dan mempermudah pemahaman al-Qur`an bagi umat Islam yang menggunakan bahasa Jawa dialek Banyumas. Di sisi lain, terjemah dengan menggunakan bahasa Banyumas ini juga sebagai upaya untuk melestarikan bahasa daerah agar terhindar dari kepunahan. Terlebih penting adalah upaya untuk mempermudah penerapan ajaran Islam yang terkandung dalam al-Qur`an ke dalam bahasa para penutur Jawa dialek Banyumasan ini.

Dengan melalui beberapa tahap mulai dari penerjemahan hingga proses pentashihan, terjemah al-Qur`an ke dalam bahasa Banyumasan ini telah memberikan manfaat bagi penguatan pengamalan isi al-Qur`an serta bagi pelestarian budaya bangsa Indonesia.

Kajian ini menjadi penting dilakukan karena merupakan studi awal tentang terjemah al-Qur`an Banyumasan. Sebab itu kajian ini berusaha mengungkap sisi persoalan bagaimana metode terjemahan ayat-ayat al-Qur`an yang terdapat dalam Al-Qur`an dan Terjemahnya Bahasa Jawa Banyumasan. Bagaimana akurasi terjemahan bahasa al-Qur`an dalam AlQur`an dan Terjemahnya Bahasa Jawa Banyumasan.

\section{B. Rekam Jejak Kehidupan KH. Ahmad Tohari}

Riwayat singkat KH. Ahmad Tohari telah banyak dipublikasikan, sekurang-kurangnya telah tercantum pada halaman belakang sejumlah bukunya. Pada lembar terakhir bukunya yang berjudul Ronggeng Dukuh Paruk, misalnya, tercantumkan bahwa KH. Ahmad Tohari lahir di desa Tinggarjaya, Kecamatan Jatilawang, Banyumas pada 13 Juni $1948 .{ }^{11}$ Ia tumbuh dalam lingkungan pesantren.

Pendidikan formal yang ditempuhnya hanya mencapai SMTA di SMAN II Purwokerto pada 1966. Namun demikian, beberapa fakultas seperti fakultas ekonomi, sosial politik, dan kedokteran pernah dijelajahinya dan kesemuanya tidak ada yang ditekuninya karena beberapa alasan. ${ }^{12}$

Di desa Tinggarjaya, Jatilawang ini KH. Ahmad Tohari mengasuh sebuah pondok pesantren dan membangun rumah tangga bersama istrinya, yaitu Syamsiah, yang bekerja

\footnotetext{
${ }^{11}$ Ahmad Tohari, Ronggeng Dukuh Paruk (Jakarta: Gramedia, 2012), hlm. 405. Lihat juga Ahmad Tohari, Bekisar Merah (Jakarta: Gramedia, 2013), hlm. 359. Yudiono K.S., Ahmad Tohari: Karya dan Dunianya (Jakarta: Grasindo, 2003), hlm. 17.

${ }^{12} \mathrm{Ibid}$.
} 


\section{Analisis Akurasi dan Karakteristik Terjemahan ..... Nurul Husna \\ Doi: doi.org/10.47454/itqan.v6i1.717}

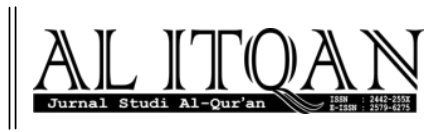

sebagai guru Sekolah Dasar setempat. ${ }^{13}$ Pondok pesantren yang diasuhnya bernama Pondok Pesantren Al-Falah yang berada di desa yang sama dengan tempat tinggalnya. ${ }^{14}$ Berada dalam lingkungan pesantren dan alam pedesaan, ia telah banyak menuliskan karya-karya, di antaranya adalah: Kubah (1980), Ronggeng Dukuh Paruk (1982), Lintang Kemukus Dini Hari (1985), Jantera Bianglala (1986), Di Kaki Bukit Cibalak (1986), Senyum Karyamin (1989), Bekisar Merah (1993), Lingkar Tanah Lingkar Air (1995)

Karya-karya yang ditulisnya bernuansa humanis. Ia begitu konsisten menyuarakan pesan moral dengan latar belakang sosial, yang mencerminkan jejak sejarah budaya masyarakat Banyumas yang primordial. Meski demikian, pesan moral yang terkandung di dalam karya-karyanya bersifat universal. ${ }^{15}$ Karakteristik karya KH. Ahmad Tohari ditandai dengan komitmennya terhadap persoalan wong cilik yang terpinggirkan. ${ }^{16}$

Proses kreatif KH. Ahmad Tohari yang kental dengan tradisi Islam pesantren menjadi akar religiusitas karya yang dihasilkan. Hal ini tampak pada karyanya yang berjudul Kubah. Sementara akar budaya Banyumas yang egaliter dan cablaka $^{17}$ telah menjadi latar kehidupan sosialnya. Karyanya merepresentasikan identitas kebanyumasan dengan indah. Ini tercermin pada banyaknya diksi lokal dan diktum berbahasa Jawa dialek Banyumasan yang khas. ${ }^{18}$

Hingga pada 2013, KH. Ahmad Tohari diminta untuk menjadi tim dalam penerjemahan al-Qur`an ke dalam bahasa daerah. Program tersebut merupakan salah satu inisiatif dari Kementerian Agama Republik Indonesia untuk turut memberikan kontribusi langsung terhadap kehidupan sosial umat Islam di daerah. KH. Ahmad Tohari adalah salah satu orang yang paling berminat untuk membangun kembali bahasa Jawa Banyumasan ini. Maka, kemudian dibentuklah tim untuk melaksanakan program tersebut. ${ }^{19}$

Motivasi utama KH. Ahmad Tohari ketika menerima permintaan tersebut adalah ketika ia membaca sebuah undangan yang di dalamnya tersuratkan QS. Al-Hujurat: 13 yang berbunyi:

\footnotetext{
${ }^{13}$ Yudiono K.S., Ahmad Tohari: Karya dan Dunianya, hlm. 4.

${ }^{14}$ Wawancara Hamidin Krazan, Banyumas, 23 Oktober 2018.

${ }^{15}$ Teguh Trianton, Identitas Wong Banyumas (Yogyakarta: Graha Ilmu, 2013), hlm. 3.

${ }^{16}$ Yudiono K.S., Ahmad Tohari: Karya dan Dunianya, hlm. 53.

${ }^{17}$ Cablaka adalah sikap terbuka secara lahir dan batin dengan pertimbangan yang matang dari apa yang diucapkan secara spontan dengan bahasa yang lugas, tegas, dan tanpa tedeng aling-aling. Keterbukaan sikap orang Banyumas terutama tercermin pada penggunaan bahasa Jawa dialek ngapak.

${ }^{18}$ Teguh Trianton, Wong Banyumas, hlm. 3.

${ }^{19}$ Wawancara dengan KH.Ahmad Tohari, Tim Penerjemah al-Qur`an Bahasa Banyumasan, Banyumas, 24 Oktober 2018.
} 


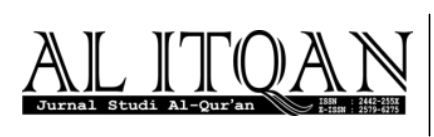

Analisis Akurasi dan Karakteristik Terjemahan .....

Nurul Husna

Doi: doi.org/10.47454/itqan.v6i1.717

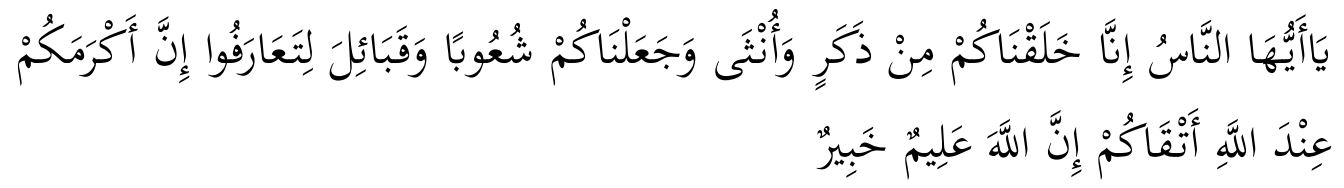

Wahai manusia! Sungguh, Kami telah menciptakan kamu dari seorang lakilaki dan seorang perempuan, kemudian Kami jadikan kamu berbangsa-bangsa dan bersuku-suku agar kamu saling mengenal. Sungguh, yang paling mulia di antara kamu di sisi Allah ialah orang yang paling bertakwa. Sungguh, Allah Maha Mengetahui, Maha teliti. ${ }^{20}$

KH. Ahmad Tohari menceritakan bahwa ia sangat terkejut dan tertegun saat itu. Bahkan Allah Subhānahu wa Ta'ālā pun telah jelas berfirman bahwa nyata adanya suku-suku dan bangsa. Dan agar konteks makna ayat tersebut tidak lenyap begitu saja, maka harus ada upaya pelestarian dalam lingkup suku dan bangsa tersebut.

Menurutnya, supaya suatu suku tetap eksis, maka jati diri mereka harus ada. Terutama jati diri itu terlihat dalam bahasa. KH. Ahmad Tohari mengaku bahwa tidak ada honor apapun untuk tim, memakai dana pribadi, dan saat dicetak pun rugi. Namun, ia tidak merasa dirugikan barang hal apapun, ia justru merasa bathi atau untung. Karena, ia merasa mengemban tugas langit, bukan lagi hanya tugas budaya. Tugas langit di sini dimaksudkan bahwa pelestarian bangsa-bangsa dan suku-suku itu termasuk dalam pelestarian terhadap sunnatullah yang telah menciptakan manusia dalam berbangsa dan suku yang berbeda-beda. ${ }^{21}$

\section{Sejarah dan Karakteristikal-Qur`an dan Terjemahnya Bahasa Jawa Banyumasan}

Awal mula kelahiran terjemah al-Qur`an ke dalam bahasa Banyumasan ini adalah sejak tahun 2011 Puslitbang Lektur dan Khazanah Keagamaan (Puslitbang LKK), Badan Litbang dan Diklat Kementerian Agama RI, menyelenggarakan program penerjemahan alQur`an ke dalam bahasa daerah bekerja sama dengan Perguruan Tinggi setempat (UIN, IAIN, STAIN). Hingga pada tahun 2015, Puslitbang LKK telah menerjemahkan al-Qur`an ke dalam sembilan bahasa. Salah satunya adalah terjemah al-Qur`an bahasa Banyumasan, Jawa Tengah yang bekerja sama dengan IAIN Purwokerto. ${ }^{22}$

Adapun menurut Ahmad Muttaqin, salah satu tim penerjemah, alasan dilakukannya penerjemahan ke dalam bahasa Banyumasan adalah, pertama, populasi penutur bahasa

\footnotetext{
${ }^{20}$ Kementerian Agama RI, Al-Qur'an dan Terjemahnya (Jakarta: PT Sinergi Pustaka Indonesia, 2012), hlm. 745.

${ }^{21}$ Wawancara dengan Ahmad Tohari,Banyumas, 24 Oktober 2018.

${ }^{22}$ Choirul Fuad Yusuf, Kepala Puslitbang Lektur dan Khazanah Keagamaan, dalam Pengantar al-Qur'an dan Terjemahnya: Bahasa Jawa Banyumasan, hlm. vii - viii
} 

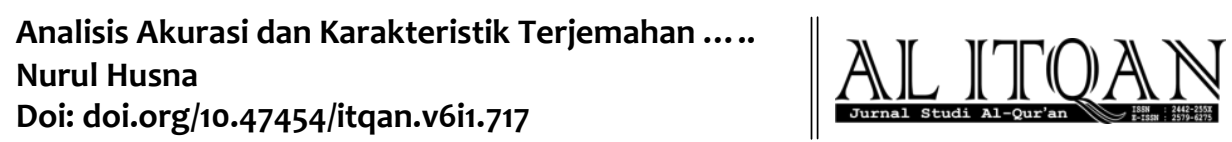

Banyumasan yang signifikan, yaitu 15 juta orang menurut statistik. Kedua, bahasa Banyumasan merupakan bahasa asli Jawa yang paling tua dan terdapat sekian marginalisasi terhadap bahasa ini. Ketiga, sebagai bentuk kontribusi kehidupan sosial bergama.

Adapun dalam proses penerjemahan al-Qur`an ke dalam bahasa daerah ini dilakukan melalui beberapa tahapan sebagai berikut ${ }^{23}$ :

1. Mushaf al-Qur`an diterjemahkan oleh Tim Penerjemah dari lembaga yang diajak bekerja sama (UIN/IAIN/STAIN). Tim penerjemah terdiri dari ulama al-Qur`an, akademisi, serta pakar bahasa dan budaya daerah yang memiliki kualifikasi, sebagai berikut:

a. Menguasai bahasa Arab sebagai bahasa al-Qur`an dengan baik.

b. Mengetahui pengetahuan dasar ilmu-ilmu al-Qur`an dan tafsir.

c. Menguasai bahasa dan budaya daerah yang menjadi sasaran terjemah.

2. Tahap diskusi internal tim. Pada tahap ini, hasil terjemahan tim-tim kecil dipresentasikan untuk dibahas, didiskusikan, atau dilakukan inter-checking sehingga menghasilkan terjemahan tim yang siap untuk divalidasi.

3. Tahap validasi terhadap hasil tim untuk melihat, mengecek, dan menceramati hasil keseluruhan secara teliti, saksama, untuk menghindari terjadinya kesalahan dalam penerjemahan, baik dalam aspek tata bahasa, makna, konteks budaya, serta ketepatan penulisannya. Tahap validasi dilakukan empat kali yang dilakukan oleh validator yang terdiri dari ahli al-Qur`an dan ahli budaya dan bahasa daerah bersangkutan. Setelah dilakukan validasi terhadap keseluruhan dan penyempurnaan atau perbaikan akhir, maka hasil terjemah lengkap 30 juz yang nilai valid secara substantif maupun kebahasaan selanjutnya diserahkan kepada Puslitbang LKK.

4. Tahap pentashihan oleh Lajnah Pentashihan Mushaf al-Qur`an (LPMA).

5. Hasil pentashihan oleh LPMA dibuktikan dengan Tanda Tashih sebagai tanda bahwa terjemahan al-Qur`an bahasa daerah tersebut terkategori sah untuk dimanfaatkan dan diedarkan ke masyarakat secara luas.

Mushaf dengan nama al-Qur`an dan Terjemahnya: Bahasa Jawa Banyumasan ini disusun oleh tim penerjemah yang terdiri dari, KH. Ahmad Tohari, A. Luthfi Hamidi, KH.

\footnotetext{
${ }^{23}$ Choirul Fuad Yusuf, dalam Pengantar al-Qur'an dan Terjemahnya: Bahasa Jawa Banyumasan, hlm. viii - ix
} 
Khariri Shofa, KH. Thoha al-Hafidz, H. Suprianto, H. Safwan Mabrur, Attabik, Nurma Ali

Ridwan, Muhyiddin Dawud, dan Ahmad Muttaqin. ${ }^{24}$ Mushaf ini telah mengalami dua kali pencetakan dan dalam hal ini yang diteliti oleh penulis adalah mushaf cetakan kedua pada Desember 2016. Mushaf ini diterbitkan oleh Puslitbang Lektur dan Khazanah Keagamaan Badan Litbang dan Diklat Kementerian Agama Republik Indonesia. Penyusunan proyek terjemah ke dalam bahasa Banyumasan ini bekerja sama dengan Institut Agama Islam Negeri (IAIN) Purwokerto.

Mushaf terjemah ini berukuran cukup besar, yaitu 21 x 29,7 cm. Tebal mushaf adalah 7,5 cm dan berisikan xviii +885 halaman. Penerjemahan ini lengkap 30 juz dan di dalamnya dilengkapi dengan daftar surah. Pada tepian tiap lembar mushaf terjemah ini dilengkapi dengan hiasan page border yang indah. Ukuran teks Arab pada ayat al-Qur`an di mushaf ini lebih besar dan dicetak tebal (bold) dibandingkan dengan ukuran teks terjemahnya. Setiap pergantian ayat juga berganti baris dalam penulisan ayat dan terjemahnya sekaligus. Begitu pula dengan setiap pergantian surat maka juga berganti halaman penulisan.

Setiap permulaan suratnya tercantumkan urutan juz, nama surah, status Makki Madani surah, urutan surah, dan jumlah ayat. Sistematika penulisan antara ayat al-Qur'an dan terjemahnya dipisahkan antara kanan dan kiri. Sebelah kanan adalah ayat al-Qur`an dan di sebelah kiri adalah terjemahnya dalam bahasa Banyumasan. Pada sebagian penerjemahannya dicantumkan footnote yang berisi keterangan-keterangan yang diperlukan.

Mushaf ini telah mendapat tanda tashih dari Lajnah Pentashihan Mushaf al-Qur`an dengan nomor 1646/LPMQ.01/TL.02.1/11/2016 dan kode A10V-II/U/0,350/XI/2016. Tanda tashih ini ditanda tangani oleh Ketua LPMQ, yaitu Muchlis M. Hanafi, dan sekretaris LPMQ, yaitu Ahsin Sakho Muhammad. Keterangan pada tanda tashih tertera disahkan pada tanggal 25 Shafar $1437 \mathrm{H}$ atau 25 November 2016 M. Beberapa anggota pentashih di antaranya; Abdul Muhaimin Zain, Ahmad Fatoni, Ali Nurudin, Ahmad Hasan al-Hakim, Binyamin Yusuf Surur dan masih banyak lagi.

Pada bagian awal mushaf terdapat sambutan dari Menteri Agama Republik Indonesia, yaitu Lukman Hakim Saifuddin. Kemudian dilanjutkan dengan sambutan dari Kepala Badan Litbang dan Diklat Kementerian Agama, yaitu Abd. Rahman Mas'ud. Lalu, terdapat pengantar yang disampaikan oleh Kepala Puslitbang Lektur dan Khazanah Keagamaan Badan

\footnotetext{
${ }^{24}$ Tim Penerjemah, al-Qur'an dan Terjemahnya: Bahasa Jawa Banyumasan (Jakarta: Puslitbang LKK, 2016), hlm. Ii.
} 
Analisis Akurasi dan Karakteristik Terjemahan .....

Nurul Husna

Doi: doi.org/10.47454/itqan.v6i1.717

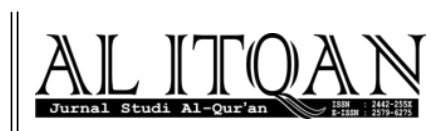

Litbang dan Diklat Kementerian Agama, yaitu Choirul Fuad Yusuf. Terakhir adalah sambutan dari Rektor IAIN Purwokerto, yaitu A. Luthfi Hamidi.

Menurut Lukman Hakim Saifudin, terjemah ini dipandang penting untuk membantu masyarakat, terutama pengguna bahasa Jawa dialek Banyumas ini, dalam memahami alQur`an yang berbahasa Arab. ${ }^{25}$ Kehadiran terjemah al-Qur`an bahasa Banyumasan ini juga menjadi sebuah jembatan masyarakat untuk berinteraksi dengan al-Qur`an. Karena, dengan membaca ayat-ayat al-Qur`an bernilai pahala, dan sekaligus memahami makna kandungannya dalam terjemahan ini.

Usaha penerjemahan ini selain memperkaya khazanah penerjemahan ke dalam bahasa daerah, terjemah al-Qur`an bahasa Banyumasan juga digunakan untuk memperluas dan mempermudah pemahaman al-Qur`an bagi umat Islam yang menggunakan bahasa Jawa dialek Banyumas. Di sisi lain, terjemah dengan menggunakan bahasa Banyumas ini juga menjadi upaya untuk melestarikan bahasa daerah untuk menghindari kepunahannya. Terlebih penting adalah upaya untuk mempermudah penerapan ajaran Islam yang terkandung dalam alQur`an ke dalam bahasa para penutur Jawa dialek Banyumasan ini.

\section{Metode Penerjemahan dalam al-Qur'an dan Terjemahnya Bahasa Jawa Banyumasan}

Seorang penerjemah memiliki metode dan caranya sendiri dalam menerjemah. Hal tersebut dapat dipengaruhi oleh pendidikan, lingkungan, dan personal diri sendiri juga dapat memberi pengaruh. Metode yang sering digunakan oleh para penerjemah dalam menerjemahkan al-Qur`an, sebagaimana yang termaktub dalam kitab-kitab ulama terdahulu, adalah harfiyyah dan tafsīiyyah. ${ }^{26}$

Begitu juga dengan mushaf al-Qur`an dan Terjemahnya Bahasa Jawa Banyumasan. Penerjemahan ini dipelopori oleh Kementerian Agama RI yang kemudian diutuskan kepada perguruan-perguruan tinggi setempat. Terjemah ke dalam bahasa daerah ini memiliki metodenya tersendiri. Tidak hanya sekedar harfiyyah atau tafsīiyyah saja, namun terdapat beberapa poin penting dalam proses penerjemahan ke dalam bahasa Banyumasan ini.

Salah satu basis utama dalam penerjemahan ke dalam bahasa daerah ini adalah $a l$ Qur`an dan Terjemahannya (dalam bahasa Indonesia), terbitan Kementerian Agama Tahun

\footnotetext{
${ }^{25}$ Tim Penerjemah, al-Qur'an dan Terjemahnya: Bahasa Jawa Banyumasan, hlm.iii.

${ }^{26}$ Mannā' bin Khalīl al-Qațtān, Mabāhīith fì 'Ulūm al-Qur'ān (t.tp: Maktabah al-Ma'ārif li al-Nashr wa alTawzì', 2000), hlm.327.
} 
2010 sebagai rujukan utama ke dalam bahasa daerah, termasuk penggunaan footnote yang tercantum di dalamnya. ${ }^{27}$ Maka, sudah jelas jika acuan yang digunakan adalah mushaf dari Kemenag tersebut. Namun, Ahmad Muttaqin mengaku bahwa tafsir diperlukan ketika ada hambatan dalam menerjemahkan dari bahasa Indonesia ke Banyumas. Karena adanya perbedaan makna, hingga menghadirkan tafsir. ${ }^{28}$ Beberapa langkah yang dilakukan dalam menerjemah ke dalam bahasa Banyumasan ini adalah, di antaranya pertama, penggunaan bahasa Indonesia. Kedua, keterbatasan kata ganti. Terakhir kontekstualisasi makna kata.

Dari keterangan di atas, secara umum, dapat dikatakan bahwa terjemah al-Qur’an dalam bahasa Banyumasan ini tergolong dalam tafsìriyyah dengan beberapa jalan atau metode yang ditempuh, yaitu adanya penggunaan diksi dalam bahasa Indonesia, kompromisasi dan kesepakatan dalam menetapkan kata ganti, dan kontekstualisasi makna.

\section{E. Analisis Akurasi Terjemah ke dalam Bahasa Banyumasan}

Bahasa daerah pada umumnya adalah bahasa yang sederhana. Berbeda dengan bahasa Arab yang memiliki citra sastra yang tinggi. Mencari padanan dari bahasa Arab ke bahasa Jawa dialek Banyumasan itu sangat sulit. Bahkan menerjemahkan dari bahasa Banyumasan ke bahasa Indonesia pun terkadang masih terasa sulit. Inilah salah satu kesulitan yang dialami para penerjemah al-Qur`an ke dalam bahasa Jawa Banyumasan. Sehingga kemudian, hal ini menimbulkan beberapa perbedaan dan kompleksifitas yang menjadi ciri khas dari terjemahan tersebut,di antaranya:

\section{Bahasa yang Berhierarki}

Pada dasarnya, karakteristik bahasa Jawa Banyumasan tidak mengenal unggahungguh atau tata krama. Namun, karena dikhawatirkan berpotensi menurunkan nuansa alQur`an yang transendental, maka diambillah keputusan kompromistis. Keputusan dan kesepakatan ini adalah untuk mengadaptasi etika dalam beberapa pokok penerjemahan sebagai bentuk pemuliaan dan pembeda atas subjek dan objek tertentu. Dalam terjemah bahasa Jawa Banyumasan ini terdapat penggunaan dua variasi tata krama bahasa yang diklasifikasikan menjadi dua yakni bahasa ngoko dan krama.

\section{a. Penggunaan Bahasa Ngoko}

\footnotetext{
${ }^{27}$ Chaerul Fuad Yusuf dalam Pengantar Kepala Puslitbang Lektur dan Khazanah Keagamaan Badan Litbang dan Diklat Kementerian Agama, al-Qur'an dan Terjemahnya: Bahasa Jawa Banyumasan (Jakarta: Puslitbang LKK, 2016), hlm. viii.

${ }^{28}$ Wawancara dengan Ahmad Muttaqin,Banyumas, 24 Oktober 2018.
} 

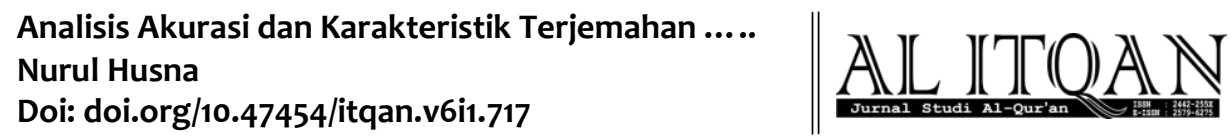

Bahasa ngoko adalah bahasa yang digunakan oleh seseorang yang berkedudukan lebih tinggi kepada yang lebih rendah atau dari yang lebih tua ke yang muda. Konteks bahasa ngoko dalan terjemah bahasa Banyumasan ini adalah kalam Allah Subhāanahu wa Ta'ālā kepada hamba-Nya. Terdapat 25 penggunaannya dalam surah al-Nisā’ ayat 1-14, yaitu penyebutan kata ganti orang kedua tunggal diredaksikan dengan kata "ko" yang artinya adalah "kamu". Seperti dalam terjemahan di bawah ini:

1) Hé menungsa! Padha semaraha maring Gustimu sing wis nyiptako kabéh sekang awak sing siji (Adam) ... (Ayat 1)

2) Padha semaraha maring Gusti Allah sing kanthi asma-Né $\underline{\text { ko }}$ padhadéné jejaluk (Ayat 1)

3) Setemené Gusti Allah tetep njaga lan ngawasi ko kabéh. (Ayat 1)

4) Aja nganti $\underline{\text { ko }}$ padha nglambangi sing apik karo sing ala (Ayat 2)

5) Lan aja nganti ko padha mangan bandhané dhéwéké kabéh bareng karo bandhamu. (Ayat 2)

6) Lan angger $\underline{\text { ko }}$ padha kewatir ora bakal téyéng temindak adil maring (hak-hak) wong wadon yatim (angger $\underline{\text { ko }}$ rabi) (Ayat 3)

7) Ning angger $\underline{k o}$ kewatir ora bakal téyéng temindak adil (Ayat 3)

8) Utawa batur-tukon wadon sing $\underline{\text { ko }}$ duwéni (Ayat 3)

9) Sing kaya kuwé mau lewih kepérék supayané $\underline{\text { ko }}$ padha ora gawé aniaya (dolim). (Ayat 3)

10) Lanwéhna mas kawin (mahar) marang wong wadon (sing $\underline{k o}$ rabi) (Ayat 4)

11) Lan aja nganti ko kabéh masrahna maring wong sing urung sempurna akalé (Ayat 5)

12) $\underline{\text { ko }}$ kabéh sing dédadékno déning Gusti Allah nggo pokok penguripan. (Ayat 5)

13) Lan aja nganti ko kabéh mangan (bandhané bocah yatim) nglewihi wates (sing) lumrah (Ayat 6)

14) lan (aja nganti ko padha) gugup (masrahna bandha kuwé) seurungé dhéwéké diwasa (Ayat 6) 


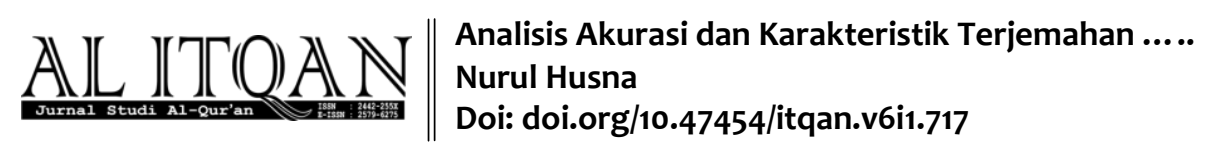

15) Banjur angger $\underline{\text { ko }}$ masrahna bandha kuwé maring dhéwéké (yatim) (Ayat 6)

16) mangka preyoga ko padha nganakna seksi-seksi (Ayat 6)

17) Gusti Allah nyaréngatna (ngudokna) maring ko kabéh ngenani (mbagi warisan nggo) anak-anakmu

18) $\underline{\text { ko }}$ kabéh ora ngerti sapa wongé neng antarané dhé-wéké kabéh sing luwih akéh pigunané tumrap $\underline{\boldsymbol{k o}}$ kabéh

19) mangka $\underline{\text { ko }}$ padha olih seprapat sekang bandha sing détinggalna

20) Para bojo olih seprapat bandha sing $\underline{\text { ko }}$ kabéh tinggal angger $\underline{\text { ko }}$ padha ora duwé anak

21) Angger ko padha duwé anak mangka bojo-bojomu olih seprawolu sekang bandha sing $\underline{\text { ko }}$ tinggal

22) wasiyat sing $\underline{k \boldsymbol{o}}$ kabeh amu gawé

Contoh-contoh di atas adalah terjemahan atas ayat-ayat yang berbicara tentang perintah dan larangan yang difirmankan oleh Allah Subhānahu wa Ta'ālà kepada hambahamba-Nya. Penggunaan bahasa ngoko seperti di atas merupakan simbol dari derajat seorang hamba di hadapan Tuhannya, yaitu tidaklah lebih tinggi. Sehingga, penggunaan bahasa ngoko tidaklah terkesan berlebihan.

\section{b. Bahasa Krama}

Bahasa Krama merupakan kebalikan dari bahasa ngoko. Bahasa krama digunakan oleh seseorang yang berkedudukan lebih rendah kepada yang lebih tinggi. Dalam hal ini digunakan sebagai bentuk penghambaan kepada Allah Subhānahu wa Ta'ālā. Contohnya adalah dalam ayat berikut:

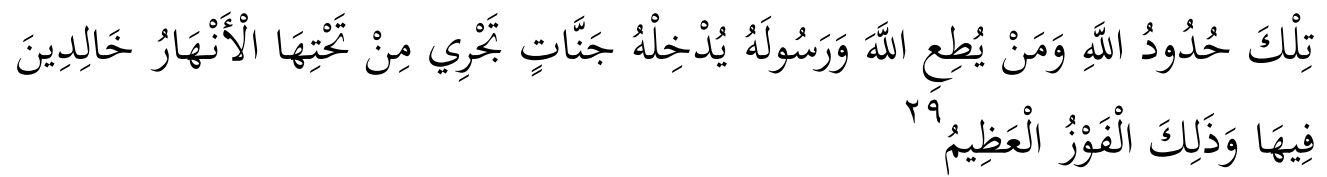

Kuwé kabéh wates-wates (hukum)é Gusti Allah. Sapa wongé manut maring Gusti Allah lan Utusan-É, Panjenengané bakal nglebokno dhéwéké maring njero suwarga sing mili kali-kali neng ngisoré, dhéwéké langgeng neng njeroné. Lan kuwé kemenangan sing agung.

\footnotetext{
${ }^{29}$ al-Qur`an, 4:13.
} 
Analisis Akurasi dan Karakteristik Terjemahan ..... Nurul Husna

Doi: doi.org/10.47454/itqan.v6i1.717

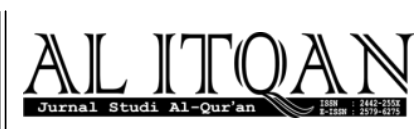

Penyebutan Allah Subḥānahu wa Ta'ālā dengan kata "Panjenengané" adalah bentuk penerjemahan dari ḍamīr "hu" dalam kata yudkhilhu. Penggunaan kata ini merupakan suatu bentuk hormat dari kata ganti yang merujuk pada Allah Subhānahu wa Ta'ālā. Selain itu, dalam terjemahan bahasa Jawa Banyumasan ini juga selalu menggunakan kata "Gusti" ketika terdapat lafal "Allah" setelahnya. Hal ini terdapat pada 17 tempat, yaitu:

1) Lan (Gusti Allah) nyipta pasangane (Hawa) (Ayat 1)

2) lan sekang sekaroné Gusti Allah nganak-pinakna lanang lan wadon sing akéh. (Ayat 1)

3) Padha semaraha maring Gusti Allah sing kanthi asma-Né ko padhadéné jejaluk.(Ayat 1)

4) Setemené Gusti Allah tetep njaga lan ngawasi ko kabéh. (Ayat 1)

5) ko kabéh sing dédadékno déning Gusti Allah nggo pokok penguripan. (Ayat 5)

6) Lan wés cukup Gusti Allah minangka pengawat-awat. (Ayat 6)

7) Lan preyoga padha wedi (maring Gusti Allah)

8) Déning merga kuwé, preyoga dhéwéké padha semarah (takwa) maring Gusti $\underline{\text { Allah }}$

9) Gusti Allah nyaréngatna (ngudokna) maring ko kabéh ngenani (mbagi warisan nggo) anak-anakmu.

10) Kiyé (anané) pepesthéné Gusti Allah.

11) Temen, Gusti Allah Maha Ngawuningani, Maha-wicaksana.

12) Kaya kuwé ketetepané Gusti Allah (Ayat 12)

13) Gusti Allah Maha Ngawuningani, Mah aris. (Ayat 12)

14) Kuwé kabéh wates-wates (hukum)é Gusti Allah (Ayat 13)

15) Sapa wongé manut maring Gusti Allah lan Utusan-É (Ayat 13)

16) Lan sapa wongé duraka maring Gusti Allah lan Utusan-É lan mlanggar wateswates hukum-É.(Ayat 14)

17) mesthi Gusti Allah nglebokna dhéwéké maring njero geni neraka (Ayat 14) 
Dalam bahasa Banyumasan, Gusti merupaka ungkapan untuk Tuhan. ${ }^{30}$ Digunakannya kata "Gusti" ini untuk menunjukkan keagungan Tuhan. Hal ini juga sebagai bentuk rasa hormat kepada Allah Subḥānahu wa Ta'ālā yang diungkapkan dalam dialek Banyumasan.

\section{Karakteristik Ungakapan Tradisional Banyumasan}

Dalam bahasa Jawa Banyumasan atau bahasa ngapak terdapat beberapa keunikan yang dalam hal ini tertuangkan dalam terjemah al-Qur`an bahasa Banyumasan di antaranya adalah bahasanya yang lugas, penggunaan diksi Jawa ngapak. Bahasa lugas yang digunakan sebagaimana contoh pada ayat ketujuh surah al-Nisā’:

"Nggo wong lanang ana hak bagéan sekang bandha tinggalané wong tua loro lan seduluré, lan nggo wong wadon ana hak bagéané (uga) sekang bandha

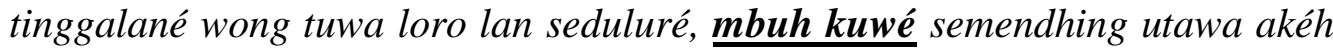
miturut bagéan sing wis détetepna."

Kata "mbuh kuwé" merupakan terjemah dari lafal مِمَّا قَلَّ مِنُُْ أَوْ كَثُرَ. Dalam terjemahnya bahasa Indonesia, diartikan sebagai "baik sedikit atau banyak". Kata "mbuh kuwé" menunjukkan penggunaan bahasa yang apa adanya seperti bahasa yang digunakan dalam lingkup sehari-hari. Penggunaan kata "mbuh kuwê" menunjukkan karakter orang Banyumasan yang cablaka. ${ }^{31}$

Namun, penggunaan kata "mbuh kuwé" dalam terjemah ini dapat merepresentasikan makna sebagai bentuk terjemah dari ayat tersebut. "Mbuh kuwé" menunjukkan adanya kebebasan dalam memilih. Memilih antara sedikit atau banyak itu terserah, "mbuh kuwé semendhing utawa akéh". Sedangkan diksi ngapak yang digunakan dapat dilihat pada surah al-Nisā’ ayat 11:

Lan nggo sekaroné rama-biyung, bagéané dhéwéké- dhéwéké sepranem (1/6) sekang bandha sing détinggalna, angger dhéwéké (sing mati) duwé anak. Angger dhéwéké (sing mati) ora duwé anak lan dhéwéké déwarisi neng ramabiyung (thok), mangka si biyung olih sepertelu.

Penyebutan kata "rama" sebanyak tiga kali, kata "biyung" sebanyak tujuh kali, dan gabungan kata keduanya "rama-biyung" sebanyak dua kali dalam surah al-Nisa' ayat 11 sampai 12.

\footnotetext{
${ }^{30}$ Ahmad Tohari, dkk, Kamus Dialek Banyumas - Indonesia (Purwokerto: Yayasan Carablaka, 2014), hlm. 104.

${ }^{31}$ Cablaka adalah lahir batinnya terbuka terhadap pertimbangan yang matang dari apa yang diucapkannya secara spontan dengan bahasa yang lugas, tanpa tédéng aling-aling atau eufemisme. Lihat Budiono Hersatoto, Banyumas: Sejarah, Budaya, Bahasa, dan Watak, hlm. 202.
} 


\section{Analisis Akurasi dan Karakteristik Terjemahan ..... Nurul Husna \\ Doi: doi.org/10.47454/itqan.v6i1.717}

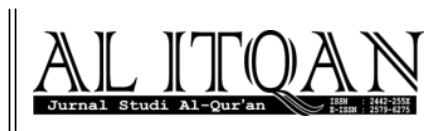

Dalam dialek Banyumasan, biyung atau biyang berarti emak, ibu. ${ }^{32}$ Dan rama adalah ayah, bapak. ${ }^{33}$ Penyebutan rama dan biyung masih lazim digunakan dalam penyebutan ayah dan ibu di wilayah Banyumasan. "Rama-biyung" juga digunakan dalam Terjemahan alQur`an Bahasa Banyumasan untuk kata abaway dan abawā seperti di atas. Ungkapan "ramabiyung" dalam terjemah ini merupakan bentuk tradisionalitas terjemahan dalam bahasa Banyumasan.

\section{Penegasan Kalimat dan Bahasa Serapan}

Selain itu penegasan kalimat dan adanya bahasa serapan juga menjadi ciri khas dari terjemahan ini. Contoh penegasan kalimat digunakan pada ayat-ayat yang berisi larangan. Terutama dalam bentuk penegasan terhadap larangan-larangan yang difirmankan Allah Subhānahu wa Ta'ālā dalam lima ayat, yaitu:

a. Aja nganti ko padha nglambangi sing apik karo sing ala,

b. lan aja nganti ko padha mangan bandhané dhéwéké kabéh bareng karo bandhamu. (Ayat 2)

c. Lan aja nganti ko kabéh masrahna maring wong sing urung sempurna akalé (Ayat 5)

d. Lan aja nganti ko kabéh mangan (bandhané bocah yatim) nglewihi wates (sing) lumrah (Ayat 6)

e. lan (aja nganti ko padha) gugup (masrahna bandha kuwé) seurungé dhéwéké diwasa. (Ayat 6)

Kata "aja nganti" merupakan sebuah bentuk penekanan suatu larangan. Kata "nganti” sendiri menegaskan akan tidak bolehnya suatu perkara. Jika dalam bahasa Indonesia, "aja nganti" bisa berarti "jangan sampai”. Berbeda dengan jika hanya menggunakan redaksi "aja" atau "jangan", dalam bahasa Indonesia. Dengan begitu, nahī atau larangan dalam ayat tersebut diterjemahkan dengan tegas dalam bahasa Jawa Banyumasan ini.

Kemudian, penegasan ini juga terdapat dalam terjemahan ayat sepuluh surah al-Nisā’, yaitu:

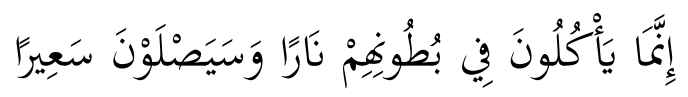

\footnotetext{
${ }^{32}$ Ahmad Tohari, dkk. Kamus Dialek Banyumas - Indonesia, hlm. 35

${ }^{33}$ Ibid., hlm. 250.
} 


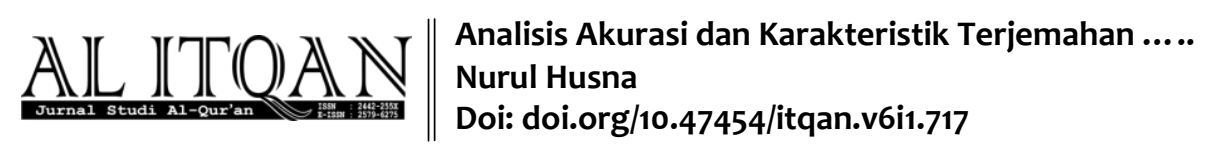

Sebeneré dhéwéké padha mangan geni neng njero wetengé (dhéwéké kabéh) lan dhéwéké padha bakal mlebu maring njero geni sing mulab-mulab (neraka).

Lafal sa'īrā dalam bahasa Arab berati nyala atau kobar. ${ }^{34}$ Dalam terjemah bahasa Indonesia, lafal sa'ťrā diterjemahkan dengan "menyala-nyala". Sedangkan dalam bahasa Jawa Banyumasan, diterjemahkan dengan "mulab-mulab" yang berarti berkobar-kobar. ${ }^{35}$ Penggunaan kata "mulab-mulab" merupakan makna yang disandingkan dengan neraka. "Mulab-mulab" sendiri merepresentasikan akan panas yang tak terhingga dan kejamnya siksa dalam neraka.

Sedangkan contoh bahasa serapan yang digunakan untuk menerjemahkan surah alNisā`ayat 3 sebagai berikut:

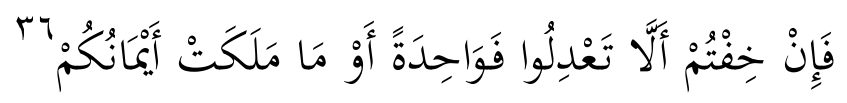

Ning angger ko kewatir ora bakal téyéng temindak adil. Mangka (rabéni) sewiji wong baé, utawa batur-tukon wadon sing ko duwéni.

Kata "batur-tukon" merupakan bentuk penerjemahan dari lafal malaka. Lafal malaka dalam bahasa Arab berarti kepunyaan, yang dimiliki, budak, hamba sahaya. ${ }^{37}$ Dalam terjemah bahasa Indoensia diartikan dengan "hamba sahaya", yang berarti abdi, budak, hamba. ${ }^{38}$ Kata "hamba sahaya" dalam terjemahan bahasa Jawa Banyumasan diartikan dengan "batur-tukon".

Pada dialek Banyumasan, kata batur berarti pembantu rumah tangga. ${ }^{39}$ Maksud dari "batur-tukon" adalah seorang pembantu atau budak yang dibeli. Kata "batur-tukon" selama ini tidak lazim digunakan dalam dialek ini. Namun, untuk menerjemahkan kata malaka yang berarti hamba sahaya, kata "batur-tukon" diadaptasi dengan maksud yang sama. Selain kata "batur-tukon" terdapat satu kata lagi yang merupakan bentuk serapan. Kata ini adalah serapan dari bahasa Arab ke dalam bahasa Jawa Banyumasan. Namun, penggunaannya merupakan pemaknaan dari terjemah bahasa Indonesia.

\footnotetext{
${ }^{34}$ Ahmad Warson Munawwir, Kamus Arab-Indonesia Al-Munawir (Surabaya: Pustaka Progresif, 1997), hlm. 633.

${ }^{35}$ Ahmad Tohari, dkk, Kamus Dialek Banyumas-Indonesia,hlm. 197.

${ }^{36}$ al-Qur`an, 4:3.

${ }^{37}$ Munawir, Kamus Arab-Indonesia, hlm. 1359.

${ }^{38}$ Pusat Bahasa, Kamus Besar Bahasa Indonesia, hlm. 1243.

${ }^{39}$ Ahmad Tohari, dkk, Kamus Dialek Banyumas-Indonesia,hlm. 27.
} 
Analisis Akurasi dan Karakteristik Terjemahan ..... Nurul Husna

Doi: doi.org/10.47454/itqan.v6i1.717

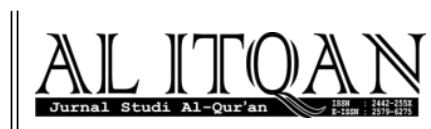

\section{F. Penulisan Terjemahan al-Qur`an Bahasa Banyumasan}

\section{Penulisan Nama Surah}

Penulisan nama surah dalam terjemah al-Qur`an ini ditulis menggunakan ejaan sesuai dengan transliterasi. Surah al-Fātiḥah (الفاتحة) ditulis dengan AL-FĀTIḤAH, dicantumkan pula jenis surahnya, Makkiyah, dan urutan surah serta jumlah ayat, yaitu surah ke-1: 7 ayat. Begitu pula penulisan nama surah البقرة ditulis dengan AL-BAQARAH, Madaniyyah, Surah ke-2: 286 ayat.

\section{Penulisan Terjemah Pembuka Surah (Fawātih al-Suwar)}

Penulisan pembuka surah (fawātih̆ al-suwār), seperti الح, الر, المر, حم dan lain-lain. Dalam terjemah al-Qur`an bahasa Banyumasan ini, pembuka surah al-Baqarah ditulis dengan "Alif Lam Mim”, sedangkan dalam surah Āli 'Imrān ditulis dengan "Alif lam mim”. Pada surah al-A'rāf ditulis dengan "Alim Lam Mim Sad”. Pada surah Yūnus ditulis dengan “Alif laam Raa”. Pada surah Hūd ditulis dengan "Alim Laam Raa”, begitu pula dengan surah Yūsuf. Pada surah al-Ra'd ditulis dengan “Alim Laam Miim Raa”.

Dari beberapa contoh di atas, terdapat inkonsistensi dalam penulisan pembuka surah (fawātih suwār) dalam terjemahan bahasa Banyumasan. Hal tersebut terjadi pada besar kecil tulisan dan penggunaan huruf vokal ganda untuk menunjukkan panjang dan pendek bacaan. Karena, terdapat penulisan pembuka surah yang tidak disertai dengan huruf vokal ganda, namun ada pula yang diberi vokal ganda.

\section{Perubahan Bentuk Kalimat}

Pada al-Qur`an dan terjemah bahasa Jawa Banyumasan surah al-Nisā' ayat 1-14 terdapat dua perubahan kalimat. Perubahan tersebut terjadi pada ayat ke-8 dan 9 .
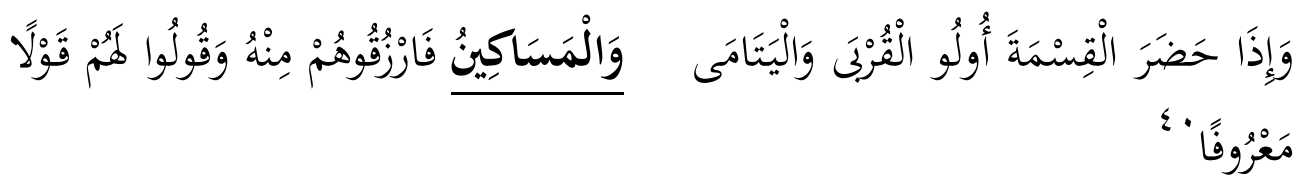

Lan angger neng wektu débaginé kuwé teka sewetarané sedulur, bocah-bocah yatim lan wong miskin, mangka wéhi dhéwéké kabéh sekang bandha kuwé (sekadaré) lan ucapna maring dhéwéké kabéh omongan sing apik.

Pada terjemahan bahasa Banyumasan, lafal al-masākīn diartikan dengan "wong miskin”. Al-Masākīn merupakan bentuk jamak dari al-miskīn yang berarti orang miskin, atau

\footnotetext{
${ }^{40}$ al-Qur`an, 4:8
} 
dalam bahasa Jawanya wong miskin. Seperti yang diketahui, bahwa dalam redaksi ayat ke-8 adalah al-masākinn yang harusnya diterjemahkan juga dengan jamak, yaitu wong-wong miskin. Namun, dalam terjemahnya bahasa Banyumasan hanya diartikan dengan wong miskin. Hal ini menunjukkan adanya ketidaksesuaian dan distorsi makna (pegurangan makna).

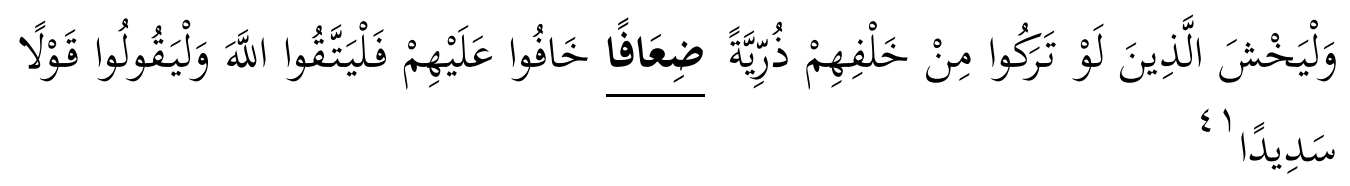

Lan preyoga padha wedi (maring Gusti Allah) wong-wong sing sekirané dhéwéké padha ninggalna turunan sing ora pideksa semburiné dhéwéké kabéh sing dhéwéké kabéh kewatir maring (kemakmuran)é. Déning merga kuwé, preyoga dhéwéké padha semarah (takwa) maring Gusti Allah, lan preyoga dhéwéké ngucap karo ucapan sing bener.

Selanjutnya adalah pada ayat ke-9 terdapat potongan ayat dan terjemahan yang digarisbawahi. Lafal $d_{i}{ }^{\prime} \bar{a} f \bar{a}$ dalam bahasa Arab berarti lemah. ${ }^{42}$ Sedangkan dalam terjemahan bahasa Banyumasan ini lafal d̦i'āfā diterjemahkan dengan "ora pideksa". Pideksa sendiri dalam bahasa Banyumasan berarti bertenaga, "ora pideksa" berarti lemah, tak bertenaga. ${ }^{43}$ Bentuk penerjemahan ini mengalami penyilangan terjemah. Seharusnya, kata ḍi' âfā bisa saja langsung diterjemahkan dengan lemah, yang dalam bahasa dialek Banyumasan adalah lembék (lemah, tak bertenaga). ${ }^{44}$ Namun, dalam hal ini diartikan dengan negasinya, yaitu "ora pideksa". Hal tersebut tidak menghilangkan makna yang dituju, hanya saja menggunakan cara menerjemah yang berbeda dari yang lain.

\section{G. Kesimpulan}

Berdasarkan pemaparan di atas, terdapat beberapa hal yang dapat disimpulkan bahwa terjemahan dalam al-Qur'an dan Terjemahnya: Bahasa Jawa Banyumasan menggunakan metode kontekstual dengan beberapa improvisasi guna menjelaskan makna yang dituju. Kadar akurasi pada terjemahan ini terdapat pada aspek-aspek berikut: Bahasa yang berhierarki, penggunaan bahasa Indonesia dan bahasa serapan dalam terjemahan, terdapat perubahan bentuk penerjemahan, namun tidak mendistorsi makna yang ada.

\footnotetext{
${ }^{41}$ al-Qur'`an, 4:9.

${ }^{42}$ Munawir, Kamus Arab-Indonesia, hlm. 825.

${ }^{43}$ Ahmad Tohari, dkk, Kamus Dialek, hlm. 234.

${ }^{44}$ Ibid., hlm. 164.
} 

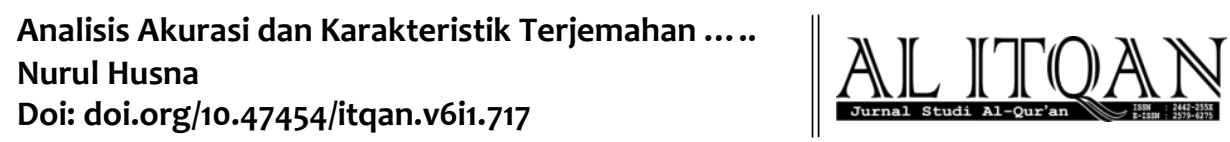

\section{DAFTAR PUSTAKA}

al-Qur`ān al-Karīm

Fatawi, M. Faisol. Seni Menerjemah. Yogyakarta: Dialektika. 2017.

Haris, Tiwalinuddin. “Al-Qur’an dan Terjemahnya Bahasa Sasak: Beberapa Catatan”. Suhuf. Jurnal kajian al-Qur'an dan kebudayaan. vol. 10. no. 1. Juni. 2017. https://doi.org/10.22548/shf.v10i1.250)

Koentjaraningrat. Kebudayaan Jawa. Jakarta: Balai Pustaka. 1994.

Munawir, Ahmad Warson. Kamus Arab - Indonesia Al-Munawir. Surabaya: Pustaka Progresif. 1997.

Mustaqim, Abdul. Epistimologi Tafsir Kontemporer. Yogyakarta: LKiS. 2011.

Penerjemah, Tim. al-Qur'an dan Terjemahnya: Bahasa Jawa Banyumasan. Jakarta: Puslitbang Lektur dan Khazanah Keagamaan Badan Litbang dan Diklat Kementrian Agama Republik Indonesia. 2016.

Pusat Bahasa. Kamus Besar Bahasa Indonesia.Jakarta: PT Gramedia Pustaka Utama. 2013.

Qațạān (al), Mannā' bin Khalīl. Mabāhịth fì 'Ulūm al-Qur'ān. t.tp: Maktabah al-Ma'ārif li alNashr wa al-Tawzì̄'. 2000.

RI, Kementerian Agama. Al-Qur`an dan Terjemahnya. Jakarta: PT Sinergi Pustaka Indonesia. 2012.

Rahman, Fazlul. "Otoritas Pemaknaan Kitab Suci: Problematika Pemikiran Edip Yuksel dalam Qur'an: A Reformist Translation”. Jurnal Studi Ilmu-Ilmu al-Qur`an dan Hadis. vol. 15. no. 2 (2014).

Risnawaty. Teori Terjemahan. Tangerang: Mahara Publishing. 2016.

Syarif. Wujud di Balik Teks: Studi Alquran dengan Pendekatan Hikmah. Bandung: Nusa Media. 2014.

Saifuddin, "Tradisi Penerjemahan Al-Qur`an ke dalam Bahasa Jawa: Suatu Pendekatan Filologis”. Suhuf. vol. 6. no. 2(2013). (https://doi.org/10.22548/shf.v6i2.28)

Tohari, Ahmad, dkk. Kamus Dialek Banyumas - Indonesia. Purwokerto: Yayasan Carablaka. 2014. 
Bekisar Merah, Jakarta: Gramedia, 2013.

Ronggeng Dukuh Paruk, Jakarta: Gramedia, 2012.

Trianton, Teguh. Identitas Wong Banyumas. Yogyakarta: Graha Ilmu. 2013.

Widyamartaya, A. Seni Menerjemahkan. Yogyakarta: Kanisius. 2012.

Yudiono K.S., Ahmad Tohari: Karya dan Dunianya, Jakarta: Grasindo, 2003.

\section{Wawancara}

Wawancara dengan Ahmad Muttaqin, Banyumas, 24 Oktober 2018.

Wawancara dengan Ahmad Tohari, Banyumas, 24 Oktober 2018.

Wawancara dengan Hamidin Krazan, Banyumas, 23 Oktober 2018.

Wawancara dengan Luthfi Hamidi, Banyumas, 24 Oktober 2018. 